\title{
Significance of Good Collateral Compensation in Symptomatic Intracranial Atherosclerosis
}

\author{
Alexander Y.L. Lau ${ }^{\mathrm{a}, \mathrm{b}}$ Edward H.C. Wong ${ }^{\mathrm{a}} \quad$ Adrian Wong $^{\mathrm{a}}$ Vincent C.T. Mok ${ }^{\mathrm{a}}$ \\ Thomas W. Leung ${ }^{\mathrm{a}}$ Ka-sing Lawrence Wong ${ }^{\mathrm{a}}$ \\ ${ }^{a}$ Division of Neurology, Department of Medicine and Therapeutics, Prince of Wales Hospital, The Chinese \\ University of Hong Kong, Hong Kong, SAR, China; ' ${ }^{b}$ Department of Neurology, University of California, \\ San Francisco, Calif., USA
}

\section{Key Words}

Acute stroke $\cdot$ Angiography $\cdot$ Intracranial disease $\cdot$

Prognosis

\begin{abstract}
Background: Collateral circulation stabilizes cerebral blood flow in patients with acute occlusion, but its prognostic role is less studied in intracranial atherosclerosis and appears different in moderate to severe stenosis. We aimed to study the associations between antegrade flow across stenosis, collateral flow via leptomeningeal anastomosis, and the neurological outcome and recurrence risk in patients with symptomatic intracranial stenosis. Methods: We examined a cohort of consecutive patients admitted for stroke or transient ischemic attack (TIA) with symptomatic intracranial stenosis confirmed by digital subtraction angiography in a singlecenter retrospective study. Angiograms were graded systematically in a blinded fashion for antegrade and collateral flow, using Thrombolysis in Cerebral Infarction ( $\mathrm{TICl}$ ) and American Society of Intervention and Therapeutic Neuroradiology/Society of Interventional Radiology (ASITN/SIR) grading, respectively, and integrated to a simple composite circulation score. Demographic and clinical variables, modi-
\end{abstract}

fied Rankin Scale (mRS) scores at 3 months, recurrent stroke or TIA in 12 months were collected. Uni- and multivariate analyses were performed to identify independent predictors of good outcome (mRS 0-2) and recurrence in a logistic regression model. Results: Among 69 patients with pure intracranial atherosclerosis $\geq 50 \%$, compromised antegrade flow ( $\mathrm{TICl} 0-2 \mathrm{a}$ ) was observed in 26 (36\%) patients and was associated with more severe arterial stenosis (mean 86 vs. $74 \%, p=0.001$ ). Poor collateral compensation resulting in a poor composite circulation score was observed in $8(12 \%)$ patients. Patients with a good circulation score $(n=61,88 \%)$ had preserved flow, which was associated with more favorable outcome (OR 7.50, 95\% Cl 1.11-50.7, $\mathrm{p}=0.04)$ and less recurrent TIA or stroke (OR $0.18,95 \% \mathrm{Cl} 0.04-0.96, \mathrm{p}=0.04)$. Prognosis was not significantly associated with antegrade or collateral grade per se. Conclusion: Good collateral compensations are more important in patients with symptomatic intracranial stenosis and compromised antegrade flow, and are associated with favorable outcome and less recurrence risk. The feasibility of composite flow assessment should be explored in future studies to identify high-risk intracranial stenosis with compromised hemodynamics.

Copyright $\odot 2012$ S. Karger AG, Basel

\section{KARGER}

Fax +4161306 1234

E-Mail karger@karger.ch

www.karger.com
C) 2012 S. Karger AG, Basel

$1015-9770 / 12 / 0336-0517 \$ 38.00 / 0$

Accessible online at:

www.karger.com/ced
Dr. Alexander Lau

Department of Medicine and Therapeutics, Prince of Wales Hospital

The Chinese University of Hong Kong

Shatin, NT, Hong Kong, SAR (China)

Tel. +852 2632 3131, E-Mail alexlau@ @uhk.edu.hk 


\section{Introduction}

Intracranial atherosclerosis is an important ischemic stroke etiology worldwide [1-3]. Patients with similar degree of arterial stenosis may have different prognosis depending on the ensuing cerebral flow status [4]. At present, there is no pragmatic and robust scheme to assess cerebral blood flow in individual patients [5]. The role and compensatory capacity of collateral circulation in preserving the ischemic penumbra was underinvestigated and debated until recent years, and recent evidence suggests collateral circulation has a definite but variable role depending on the severity of arterial stenosis [4-6].

Collateral circulation preserves perfusion and stabilizes cerebral blood flow in acute occlusion and chronic atherosclerosis [7]. Collateral flow via leptomeningeal anastomosis in patients with symptomatic atherosclerosis - unlike acute occlusion - is seldom examined adequately without catheter-based angiograms [8-10]. To further address the role of collateral circulation among patients with symptomatic intracranial atherosclerosis, we performed an angiogram-based study in a cohort of Chinese patients with pure intracranial atherosclerosis. We hypothesized that collateral compensation is more important in patients with compromised flow across the stenosed artery, and compensated cerebral blood flow is associated with better recovery and less recurrence.

\section{Methods}

This was a retrospective single-center study approved by the institutional review board. All patients gave informed consent. We identified patients with pure symptomatic intracranial atherosclerosis from the stroke registry of a university hospital in Hong Kong. Consecutive patients admitted for ischemic stroke or transient ischemic attack (TIA) with non-invasive imaging showing extra- or intracranial large artery atherosclerosis were further evaluated by digital subtraction angiogram (DSA) as part of their diagnostic workup. Data collected included age, gender, blood pressure, fasting blood glucose levels, lipid profile, and medical history of hypertension, diabetes mellitus, hyperlipidemia, atrial fibrillation, and ischemic heart disease. Index stroke severity on admission, measured by National Institute of Health Stroke Scale (NIHSS), and functional outcome at 3 months, measured by modified Rankin Scale (mRS) were performed by stroke nurses or neurologists. Patients were excluded if the vascular etiology was nonatherosclerotic, including vasculitis, dissection, or anomaly such as fenestration, or if they had concurrent significant extracranial stenosis ( $>50 \%$ ), or atrial fibrillation. The culprit artery was defined as the symptomatic intracranial artery (internal carotid, middle cerebral, anterior cerebral and vertebral-basilar artery) with stenosis identified on MR angiogram and relevant acute lesions of index stroke identified on diffusion-weighted imaging on
MRI, or with stereotypical ischemic symptoms attributed to the corresponding arterial distribution for TIA. Symptomatic stenosis is confirmed on DSA and the degree of stenosis was measured on angiogram using criteria in the Warfarin-Aspirin Symptomatic Intracranial Disease (WASID) trial [11].

Patients who subsequently underwent angioplasty and stenting fulfilled the criteria as described elsewhere [12]. In brief, these patients had symptomatic intracranial stenosis $\geq 70 \%$ or stenosis $\geq 50 \%$ with recurrent ischemia despite medical therapy, and the diameter of vessel immediately adjacent to the stenosis was $\geq 2$ $\mathrm{mm}$. During procedure, predilation of stenotic lesion by an undersized angioplasty balloon at $80 \%$ of native vessel diameter (Gateway PTA balloon catheter; Boston Scientific, Natick, Mass., USA) was followed by stent placement using the Wingspan system (Boston Scientific). These patients received double antiplatelets, aspirin $80 \mathrm{mg}$ and clopidogrel $75 \mathrm{mg}$ daily, from at least 3 days before to 6 weeks after procedure. All patients received aspirin lifelong otherwise. All patients in the study were followed up regularly and received treatment at the neurology specialty clinic for at least 2 years, with aggressive risk factors control for hypertension, diabetes, and hyperlipidemia using appropriate medications according to published guidelines $[13,14]$.

\section{Angiogram Assessment - Antegrade and Collateral Flow}

The antegrade flow across the culprit artery and collateral flow via circle of Willis and leptomeningeal anastomosis were assessed using the diagnostic pretreatment DSA angiograms by the Thrombolysis in Cerebral Infarction (TICI), and the American Society of Intervention and Therapeutic Neuroradiology/Society of Interventional Radiology (ASITN/SIR) for antegrade and collateral grading, respectively [15]. The independent assessors were blinded to the clinical profiles and outcomes of patients, except the site of arterial lesion from MR angiogram. TICI 0 corresponds to no perfusion or nil antegrade flow beyond the point of occlusion. TICI 1 corresponds to penetration with minimal perfusion; contrast passes beyond obstruction but fails to opacify the entire distal cerebral bed for the duration of the angiographic run. TICI 2 corresponds to partial perfusion; with contrast passes beyond the obstruction and opacify the arterial bed distal to the obstruction, but the rate of entry of contrast into the distal cerebral bed and/or its rate of clearance from the distal bed were perceptibly slower from comparable areas, usually the opposite cerebral artery. TICI 2 was further divided into TICI $2 \mathrm{a}$, with partial filling $(<2 / 3)$ of the entire vascular territory, and TICI 2 b, with complete but slower filling of the expected vascular territory. TICI 3 corresponded to antegrade flow distal to the obstruction occurred as promptly as into the obstruction and clearance from the distal bed was as rapid as from an opposite cerebral artery. TICI grades 0,1 , or 2 a were considered as 'compromised' antegrade flow, and TICI grades $2 \mathrm{~b}$ and 3 are considered as 'preserved' antegrade flow.

In the ASITN/SIR collateral flow grading system, grade 0 corresponded to no collaterals visible to the ischemic site; grade 1 corresponded to slow collaterals to the periphery of the ischemic site with persistence of some of the defect; grade 2 corresponded to rapid collaterals to the periphery of the ischemic site with persistence of some of the defect and to only a portion of the ischemic territory; grade 3 corresponded to collaterals with slow but complete angiographic blood flow of the ischemic bed by the late venous phase, and grade 4 corresponded to complete and rapid collateral blood flow to the vascular bed in the entire ischemic terri- 
Table 1. Composite circulation score integrating antegrade and collateral flow status

\begin{tabular}{llllllll}
\hline & \multicolumn{9}{l}{ Score } \\
\cline { 3 - 7 } & & 0 & 1 & 2 & 3 & 4 \\
\hline I. Antegrade grade & TICI & 0 & 1 & $2 \mathrm{a}$ & $2 \mathrm{~b}$ & 3 \\
II. Collateral grade & ASITN/SIR & 0 & 1 & 2 & 3 & 4
\end{tabular}

Composite circulation score $=$ I + II.

tory by retrograde perfusion. ASITN/SIR collateral grades $0-1$ were considered as poor collateral circulation, while collateral grades 2 or 4 were considered as good collateral circulation [4].

\section{Composite Circulation Score}

A simple composite circulation score was constructed to integrate the antegrade and collateral flow status by summation of scores of 0-4 assigned to corresponding TICI and ASITN/SIR grading (table 1$)$.

A cut-off score of 3 was used to define poor circulation score $(\leq 3)$ and good circulation score $(>3)$. Poor circulation score represented patients with poor antegrade circulation (TICI $0-2 \mathrm{a}$ ) with poor collateral compensation (ASITN/SIR 0-1), and overall compromised cerebral flow. Good circulation score represented patients with either poor antegrade circulation with good collateral compensation, or preserved antegrade flow with fair or good collateral compensation, and overall preserved cerebral flow. For instance, a patient with poor antegrade flow (TICI 2a) with minimal collateral compensation (ASITN/SIR 1) has a poor circulation score of 3 . The same patient with better collateral compensation (ASITN/SIR $\geq 2$ ) would have a good circulation score $\geq 3$. A patient with preserved antegrade flow (TICI $\geq 2 \mathrm{~b}$ ) will have a good circulation score $\geq 3$ which is not dependent on collateral circulation status. On the other hand, a patient with very poor antegrade flow (TICI 1) needs better grade collateral compensation (ASITN/ SIR $\geq 3$ ) in order to achieve a good circulation score $\geq 3$.

\section{Outcomes Measures}

The primary outcome was functional outcome at 3 months measured by mRS, and dichotomized to favorable (mRS 0-2) and unfavorable (mRS $>2$ ) for analysis. Secondary outcome was recurrent ischemic stroke in 12 months, which was retrieved from the electronic patient record. Ischemic stroke was defined as acute focal neurological deficit lasting $\geq 24 \mathrm{~h}$, and not attributed to hemorrhage by neuroimaging.

\section{Statistical Analysis}

SPSS 18.0 for Windows was used as the statistical software for analysis. The mean and standard deviation was calculated for continuous variables including age, arterial stenosis, blood pressure, $\mathrm{HbA}_{1 \mathrm{c}}$ levels, and lipid levels. The proportion of patients in each variable was reported for categorical variables, including gender, medical history of hypertension, diabetes, lipid disorder, history of smoking, coronary artery disease, and the symptomatic intracranial artery. NIHSS was reported in median with in-
Table 2. Baseline demographics of patients with good and poor circulation score

\begin{tabular}{|c|c|c|c|}
\hline & $\begin{array}{l}\text { Good circu- } \\
\text { lation score } \\
(\mathrm{n}=61)\end{array}$ & $\begin{array}{l}\text { Poor circu- } \\
\text { lation score } \\
(\mathrm{n}=8)\end{array}$ & $\begin{array}{l}\mathrm{p} \\
\text { value }\end{array}$ \\
\hline Age, years & $61.4 \pm 11.0$ & $65.4 \pm 7.7$ & 0.22 \\
\hline Female & $17(28 \%)$ & $2(25 \%)$ & 1.00 \\
\hline Systolic blood pressure, $\mathrm{mm} \mathrm{Hg}$ & $146 \pm 18$ & $148 \pm 30$ & 0.90 \\
\hline Diastolic blood pressure, $\mathrm{mm} \mathrm{Hg}$ & $84 \pm 12$ & $79 \pm 10$ & 0.38 \\
\hline Fasting blood glucose, $\mathrm{mmol} / \mathrm{l}$ & $6.5 \pm 2.0$ & $8.0 \pm 2.9$ & 0.19 \\
\hline $\mathrm{HbA}_{1 \mathrm{c}}, \%$ & $7.3 \pm 2.0$ & $10.5 \pm 2.1$ & 0.10 \\
\hline LDL cholesterol, mmol/l & $3.4 \pm 1.0$ & $3.2 \pm 1.3$ & 0.77 \\
\hline HDL cholesterol, $\mathrm{mmol} / \mathrm{l}$ & $1.2 \pm 0.4$ & $1.2 \pm 0.4$ & 0.79 \\
\hline Triglyceride, mmol/l & $2.0 \pm 1.9$ & $1.5 \pm 0.9$ & 0.17 \\
\hline Hypertension & $39(64 \%)$ & $5(63 \%)$ & 1.00 \\
\hline Diabetes & $21(34 \%)$ & $3(38 \%)$ & 1.00 \\
\hline Lipid disorder & $52(87 \%)$ & $5(63 \%)$ & 0.11 \\
\hline Smoking history & $24(39 \%)$ & $5(63 \%)$ & 0.45 \\
\hline Coronary artery disease & $2(3 \%)$ & 0 & 1.00 \\
\hline Acute NIHSS, median (IQR) & $3(2-4)$ & $3.5(3-7.5)$ & 0.04 \\
\hline Symptomatic artery & & & 0.35 \\
\hline Internal carotid & $11(18 \%)$ & $3(38 \%)$ & \\
\hline Middle cerebral & $50(82 \%)$ & $5(62 \%)$ & \\
\hline Stenosis of symptomatic artery & & & 0.001 \\
\hline Moderate stenosis (50-70\%) & $12(20 \%)$ & 0 & \\
\hline Severe stenosis $(70-99 \%)$ & $48(79 \%)$ & $4(50 \%)$ & \\
\hline Occlusion (100\%) & $1(2 \%)$ & $4(50 \%)$ & \\
\hline Mean percentage stenosis & $76 \pm 15$ & $93 \pm 11$ & 0.008 \\
\hline Angioplasty & $27(44 \%)$ & $2(25 \%)$ & 0.45 \\
\hline
\end{tabular}

terquartile range (IQR), and Mann-Whitney $\mathrm{U}$ test was used to assess difference between groups. The difference between patients with good and poor circulation score was assessed by Student's t test for continuous variables and Fisher's exact test for categorical variable where appropriate. Uni- and multivariate analysis performed using putative predictors with $\mathrm{p}$ values $<0.10$ was entered in the stepwise logistic regression model. Statistical significance was considered at $\mathrm{p} \leq 0.05$ and was two-sided.

\section{Results}

Between January 2006 and August 2009, 304 patients underwent DSA after acute ischemic stroke for diagnostic evaluation and workup for endovascular intervention. 95 patients who had intracranial stenosis were screened for the current study. 26 patients were excluded for the following reasons: 10 had concurrent significant extracranial atherosclerosis, 6 had vertebrobasilar artery stenosis, 5 had non-atherosclerotic lesions, and 5 had incomplete angiogram assessment for grading. 69 patients with pure intracranial atherosclerosis in the anterior cir- 
Table 3. Univariate associations of baseline characteristics and outcomes

\begin{tabular}{|c|c|c|c|c|c|c|}
\hline mRS $0-2$ at 3 months & $\begin{array}{l}\text { Good outcome } \\
(n=62)\end{array}$ & $\begin{array}{l}\text { Poor outcome } \\
(\mathrm{n}=7)\end{array}$ & $\mathrm{p}$ value & OR & $95 \% \mathrm{CI}$ & $\mathrm{p}$ value \\
\hline Age & $62.1 \pm 10.9$ & $65.4 \pm 9.2$ & 0.38 & 0.97 & $0.90-1.05$ & 0.42 \\
\hline Hypertension & $41(66 \%)$ & $3(43 \%)$ & 0.25 & 2.60 & $0.53-12.72$ & 0.24 \\
\hline Diabetes & $22(36 \%)$ & $2(29 \%)$ & 1.00 & 1.38 & $0.25-7.68$ & 0.72 \\
\hline Lipid disorder & $50(82 \%)$ & $11(18 \%)$ & 0.59 & - & & \\
\hline Smoking history & $28(45 \%)$ & $1(14 \%)$ & 0.26 & 5.09 & $0.58-44.86$ & 0.14 \\
\hline Angioplasty & $29(47 \%)$ & 0 & 0.02 & - & & \\
\hline Severe stenosis & $47(81 \%)$ & $5(83 \%)$ & 1.00 & 0.68 & $0.075-6.20$ & 0.73 \\
\hline Good antegrade flow & $39(63 \%)$ & $4(57 \%)$ & 1.00 & 1.27 & $0.26-6.19$ & 0.77 \\
\hline Good collateral flow & $56(90 \%)$ & $5(72 \%)$ & 0.18 & 3.28 & $0.54-19.98$ & 0.20 \\
\hline Good circulation score & $57(92 \%)$ & $4(57 \%)$ & 0.03 & 8.55 & $1.58-49.40$ & 0.016 \\
\hline Hypertension & $7(78 \%)$ & $37(32 \%)$ & 0.47 & 2.12 & $0.42-11.39$ & 0.36 \\
\hline Diabetes & $4(44 \%)$ & $20(33 \%)$ & 0.71 & 1.60 & $0.38-6.62$ & 0.52 \\
\hline Lipid disorder & $7(78 \%)$ & $50(85 \%)$ & 0.63 & 1.59 & $0.28-8.90$ & 0.60 \\
\hline Smoking history & $1(11 \%)$ & $28(47 \%)$ & 0.11 & 0.14 & $0.02-1.18$ & 0.09 \\
\hline NIHSS, median (IQR) & $2(1.5-3)$ & $3(2-4.5)$ & 0.20 & 1.04 & $0.79-1.38$ & 0.78 \\
\hline Angioplasty & $1(11 \%)$ & $28(47 \%)$ & 0.07 & 0.14 & $0.017-1.21$ & 0.08 \\
\hline Severe stenosis & $6(75 \%)$ & $46(82 \%)$ & 0.64 & 0.65 & $0.11-3.72$ & 0.63 \\
\hline Good antegrade flow & $5(56 \%)$ & $38(63 \%)$ & 0.72 & 0.72 & $0.18-2.98$ & 0.65 \\
\hline Good collateral flow & $7(78 \%)$ & $54(90 \%)$ & 0.28 & 0.39 & $0.07-2.31$ & 0.39 \\
\hline Good circulation score & $6(66 \%)$ & $55(92 \%)$ & 0.06 & 0.18 & $0.04-0.96$ & 0.04 \\
\hline
\end{tabular}

culation were used in the analysis, including 12 with moderate stenosis (50-69\%), 52 with severe stenosis (70$99 \%)$, and 5 with complete (100\%) occlusion. The distributions of arterial involvement were internal carotid artery $(\mathrm{n}=14,20 \%)$ and middle cerebral artery $(\mathrm{n}=55$, $80 \%)$. Among these patients, 29 (42\%) underwent successful endovascular angioplasty and stenting.

\section{Antegrade and Collateral Circulation Status}

With progressive stenosis, antegrade flow worsened and ceased when complete occlusion was evident; compromised flow (TICI grade $0-2 \mathrm{a}$ ) was found in 1 of 12 (8\%) patients with moderate stenosis (50-69\%) and 20 of $52(53 \%)$ patients with severe stenosis $(70-99 \%)(\mathrm{p}=$ $0.001)$. Integrating antegrade and collateral grading to calculate the composite circulation score identified 61 $(88 \%)$ patients with good circulation score $(\geq 3)$ and 8 $(12 \%)$ patients with poor circulation score $(<3)$. The baseline characteristics of patients with good or poor circulation score are shown in table 2. Patients with good circu- lation score were slightly younger (61.4 vs. 65.4 years), and had a similar risk factor profile as compared to patients who had poor circulation score, except better control of underlying diabetes $\left(\mathrm{HbA}_{1 \mathrm{c}} 7.3\right.$ vs. $\left.10.5 \%\right)$, but the difference did not reach statistical significance. The commonest arterial lesion was middle cerebral artery (82 and $62 \%)$. Patients with good circulation score had significantly less severe arterial stenosis (mean stenosis 76 vs. $93 \%, \mathrm{p}=0.008$ ), and less complete occlusions ( 2 vs. $50 \%$, $\mathrm{p}=0.001)$. The index stroke severity was also slightly less severe for patients with good circulation score (median NIHSS 3 vs. 3.5, p = 0.04). $27(44 \%)$ and $2(25 \%)$ patients in the good and poor circulation score group underwent angioplasty and stenting $(\mathrm{p}=0.45)$.

\section{Circulation Status and Neurological Outcomes mRS at 3 Months}

Most patients ( $\mathrm{n}=61,90 \%$ ) in the cohort had favorable outcome, defined as mRS $0-2$. Table 3 shows the associations of clinical variables, circulation status, and good 
Table 4. Characteristics of patients who underwent angioplasty and stenting

\begin{tabular}{|c|c|c|c|}
\hline & $\begin{array}{l}\text { Angioplasty }+ \\
(\mathrm{n}=29)\end{array}$ & $\begin{array}{l}\text { Angioplasty - } \\
(\mathrm{n}=40)\end{array}$ & $\begin{array}{l}\mathrm{p} \\
\text { value }\end{array}$ \\
\hline Age, years & $59.4 \pm 10.7$ & $64.6 \pm 10.4$ & 0.04 \\
\hline Female & $6(20 \%)$ & $14(33 \%)$ & 0.29 \\
\hline Symptomatic artery & & & 0.10 \\
\hline Internal carotid & $10(33 \%)$ & $7(16 \%)$ & \\
\hline Middle cerebral & $20(67 \%)$ & $36(84 \%)$ & \\
\hline Stenosis of symptomatic artery & & & 0.09 \\
\hline Moderate stenosis (50-70\%) & $5(17 \%)$ & $8(19 \%)$ & \\
\hline Severe stenosis (70-99\%) & $25(83 \%)$ & $29(67 \%)$ & \\
\hline Mean percentage stenosis & $76 \pm 11$ & $80 \pm 18$ & 0.36 \\
\hline Good antegrade flow & $20(69 \%)$ & $23(58 \%)$ & 0.45 \\
\hline Good collateral flow & $28(93 \%)$ & $37(86 \%)$ & 0.46 \\
\hline Good circulation score & $27(93 \%)$ & $34(85 \%)$ & 0.45 \\
\hline
\end{tabular}

functional outcome at 3 months. There was no significant association between baseline characteristics and good outcomes. The proportion of patients with favorable outcome was greater in those with good circulation score $(92$ vs. $57 \%, p=0.03)$. Similar but non-significant trends were noted in patients with good antegrade flow (63 vs. $57 \%$ ) and good collateral flow ( 90 vs. $72 \%$ ). All patients who underwent angioplasty $(n=29)$ achieved favorable outcome at 3 months. In univariate analysis, good circulation score $\geq 3$ was significantly associated with favorable outcome (OR 8.55, 95\% CI 1.58-49.4, $\mathrm{p}=0.016$ ). After adjusting for age, NIHSS score, and angioplasty, a good circulation score remained independent in predicting favorable outcome (adjusted OR 7.50, 95\% CI 1.11-40.7, $\mathrm{p}=0.039$ ).

Recurrent Stroke or TIA in 12 Months

Recurrent stroke $(\mathrm{n}=8)$ and TIA $(\mathrm{n}=1)$ was recorded in $9(13 \%)$ patients in 12 months after the qualifying event, in which 6 (67\%) occurred in the same the culprit artery territory, and within the first 3 months. Six (10\%) patients with good circulation score had recurrent stroke, although the result did not reach statistical significance $(\mathrm{p}=0.06)$. One (3\%) patient who had angioplasty developed TIA after procedure. In univariate analysis, good circulation score was associated with less recurrence (OR $0.18,95 \%$ CI $0.04-0.96, \mathrm{p}=0.04$ ).

\section{Circulation Status of Patients Who Underwent Angioplasty and Stenting}

The characteristics and hemodynamic status of patients who underwent angioplasty and stenting is shown
Table 5. Outcomes of patients with intracranial stenosis without undergoing angioplasty

\begin{tabular}{lrll}
\hline & $\begin{array}{l}\text { Good circu- } \\
\text { lation score } \\
(\mathrm{n}=34)\end{array}$ & $\begin{array}{l}\text { Poor circu- } \\
\text { lation score } \\
(\mathrm{n}=6)\end{array}$ & p value \\
\hline mRS 0-2 at 3 months & $31(91 \%)$ & $3(50 \%)$ & 0.051 \\
TIA/stroke in 12 months & $5(15 \%)$ & $2(33 \%)$ & 0.27 \\
\hline
\end{tabular}

in table 4. Patients who had angioplasty were slightly younger (59.4 vs. 64.6 years, $\mathrm{p}=0.04$ ). There was otherwise no significant difference of antegrade and collateral flow status between the groups of patients.

A subgroup analysis was performed on 40 patients who did not undergo angioplasty (table 5). There was a similar trend of more favorable outcome in patients with good circulation score compared to those with poor circulation score ( 91 vs. $50 \%, \mathrm{p}=0.051$ ), as well as fewer recurrent events ( 15 vs. $33 \%, \mathrm{p}=0.27$ ).

\section{Discussion}

In this retrospective cohort study using composite vascular assessment in intracranial atherosclerosis, we found good collateral compensation in patients with compromised antegrade flow was associated with more favorable outcome and lower risk of recurrent stroke. This adds to the growing evidence of prognostication role by collateral circulation $[4,5,16,17]$. Unlike acute arterial occlusion with complete cessation of antegrade flow and prognosis which is independently predicated by collateral flow status [18-21], our study suggests that composite antegrade and collateral assessment is feasible and useful in the prognostication of patients with chronic intracranial atherosclerosis.

The first systematic studies on the prognostication of collateral circulation were in patients with carotid stenosis. In the North American Symptomatic Endarterectomy Trial (NASCET) the 2-year risk of hemisphere stroke in patients with severe internal carotid artery stenosis was significantly reduced in the presence of collaterals (found in $9.7 \%$ patients) from 27.8 to $11.3 \%$ ( $\mathrm{p}=0.005$ ), and the perioperative risk of hemisphere stroke for patients who had carotid endarterectomy was reduced from 4.9 to $1.1 \%$ in the presence of collaterals on angiograms [22]. Data on intracranial stenosis was lacking until recently; an important study by Liebeskind et al. [4] on pa- 
Fig. 1. Composite flow assessment in 2 patients with severe intracranial atherosclerosis. a, b A 55-year-old female had symptomatic left MCA M1 stenosis (81\%) and left internal borderzone infarcts. Her angiogram showed compromised antegrade perfusion with partial filling of MCA territory (a). Good collateral compensation via leptomeningeal anastomosis between ACA/MCA (arrow) was evident in the late arterial and venous (b) phases of angiogram. She had excellent recovery and no recurrence in 12 months. c, d A 75-yearold female had symptomatic right MCA M1 stenosis (80\%) with multiple pial and borderzone infarcts. Her angiogram showed poor antegrade flow with minimal perfusion beyond the stenosis (c). Poor collateral compensation via leptomeningeal anastomosis, including between PCA/ MCA (d), could have accounted for the poor recovery and early recurrent stroke. $\mathrm{ACA}=$ Anterior cerebral artery; $\mathrm{MCA}=$ middle cerebral artery; $\mathrm{PCA}=$ posterior cerebral artery.

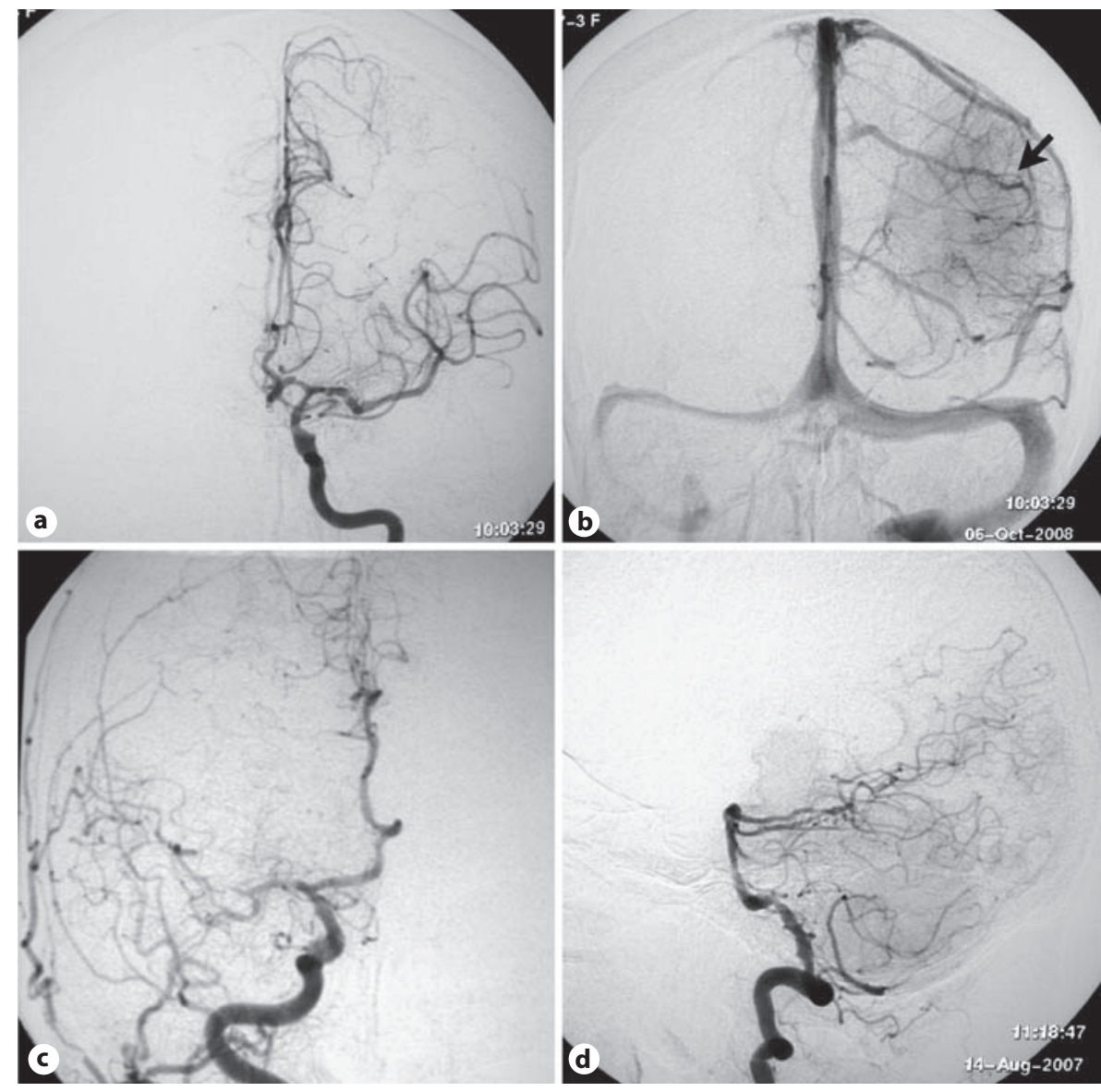

tients recruited in the pivotal WASID trial reported different prognostic role of collaterals among patients with intracranial atherosclerosis. Liebeskind et al. reported in patients with severe stenosis (70-99\%) that more extensive collaterals diminished the risk of subsequent territorial stroke (HR 4.60, $\mathrm{p}=0.04$ ), whereas in patients with moderate stenosis, the presence of collaterals was associated with a greater likelihood of subsequent stroke (HR $0.18, \mathrm{p}<0.0001$ ), and concluded that collaterals have a protective role with severe stenosis and help to identify unstable milder stenosis. Our current study might help to explain the varying prognostic role of collaterals in patients with moderate stenosis. Antegrade flow was preserved in about half of the patients with moderate to severe stenosis; perfusion was adequate across the stenosed segment to corresponding downstream territory. A lesser role was played by collateral compensation in this group of patients. On the other hand, the other half of the patients had compromised antegrade flow and the downstream territory was at risk of ischemia and infarction.
Collateral circulation played an important role in compensating and stabilizing cerebral blood flow (fig. 1). Nevertheless, once chronic atherosclerosis reaches an advanced stage with complete occlusion, even good collateral circulation may not be adequate to compensate circulation, with resultant poor circulation and poor prognosis. Collateral circulation can be considered as a surrogate marker of an unstable system; good collateral compensation is crucial in severe to critical stenosis with inevitable compromised flow. On the other hand, it is difficult to infer, based on the degree of arterial stenosis alone, which patients with moderate to severe stenosis had compromised flow. Further studies addressing means to stratify risk in this group of patients would have a tremendous impact on treatment decisions targeted at revascularization or collateral augmentation.

The favorable neurological outcomes among patients with good collateral compensation could be linked to the neuroplasticity theory. Neuroplasticity in post-stroke brain has been shown to occur by perilesional recruit- 
ment by synaptogenesis or dendritic arborization [23]. An animal model demonstrated restoration of perfusion to ischemic borders by collateral circulation via arterioles and new capillaries in Wistar rats after surgical ligation of MCA branches [24]. Collateral circulation potentially provides blood supply to the perilesional brain parenchyma to facilitate repair and recovery, and may partially explain why patients with good collateral flow had better neurological recovery [3].

The limitations of the study are attributed to the small sample size, hypothesis-generating and retrospective design, which is bias-prone and underpowered to produce generalizable results. The patients were recruited in a single center and of relatively mild stroke only, and were subjected to selection bias. Event rates were relatively low and limit the robustness of the statistical model. The assessment on collateral circulation focused on circle of Willis and leptomeningeal anastomosis, and alternate routes of collateral flow from the external carotid system were not fully explored [8]. Although the use of invasive angiograms allowed accurate anatomical assessment of culprit arterial lesions and unique qualitative assessment of cerebral blood flow, this strategy is less pragmatic to be incorporated in a risk-stratification model. Moreover, we used pretreatment angiograms for assessment patients who underwent endovascular angioplasty and stenting. The immediate and delayed changes of cerebral hemodynamics after the procedure may confound the initial composite flow assessment [25]. Lastly, we used an intuitive composite circulation score to assess cerebral flow by simple summation of antegrade and collateral grade scores; while it accounts for the need of more competent collaterals with worsening antegrade flow, the assumption of equal contribution of antegrade and collateral flow to cerebral blood flow by quantitative grading may not be accurate. Ideally, future studies on a predictive model for prognostication can incorporate assessment of collateral circulation by non-invasive imaging techniques, such as MR-, CT-, or transcranial Doppler (TCD)based studies, to devise a comprehensive cerebral flow assessment scheme $[9,10,17,26]$. We did not correlate our DSA and TCD or MR angiogram findings in the current study. Nevertheless, since most patients with symptomatic intracranial atherosclerosis would undergo further non-invasive neuroimaging to assess vascular status, development of a robust and pragmatic imaging-based risk stratification can potentially identify more suitable candidates for aggressive therapeutics, such as intracranial stenting [27].

\section{Conclusion}

Good collateral compensation in patients with symptomatic intracranial atherosclerosis and compromised antegrade flow was associated with favorable neurological outcomes. Composite vascular assessment is feasible and should improve prognostication by identifying patients with symptomatic intracranial atherosclerosis at higher risk of poor recovery and recurrence. Large prospective studies are warranted to validate these findings.

\section{Acknowledgements}

A.Y.L.L. is a recipient of the Croucher Foundation Fellowship and Henry Leung Fellowship.

\section{References}

1 Wong LK: Global burden of intracranial atherosclerosis. Int J Stroke 2006;1:158-159.

-2 Gorelick PB, Wong KS, Bae HJ, Pandey DK: Large artery intracranial occlusive disease: a large worldwide burden but a relatively neglected frontier. Stroke 2008;39:2396-2399.

- 3 Han JH, Wong KS: Is counterpulsation a potential therapy for ischemic stroke? Cerebrovasc Dis 2008;26:97-105.

44 Liebeskind DS, Cotsonis GA, Saver JL, Lynn MJ, Turan TN, Cloft HJ, Chimowitz MI: Collaterals dramatically alter stroke risk in intracranial atherosclerosis. Ann Neurol 2011; 69:963-974.
5 Shuaib A, Butcher K, Mohammad AA, Saqqur M, Liebeskind DS: Collateral blood vessels in acute ischaemic stroke: a potential therapeutic target. Lancet Neurol 2011;10: 909-921.

6 Brozici M, van der Zwan A, Hillen B: Anatomy and functionality of leptomeningeal anastomoses: a review. Stroke 2003;34:2750 2762.

7 Liebeskind DS: Understanding blood flow: the other side of an acute arterial occlusion. Int J Stroke 2007;2:118-120.

8 Liebeskind DS: Collateral circulation. Stroke 2003;34:2279-2284
-9 Choi JY, Kim EJ, Hong JM, Lee SE, Lee JS Lim YC, Kim HS: Conventional enhancement CT: a valuable tool for evaluating pial collateral flow in acute ischemic stroke. Cerebrovasc Dis 2011;31:346-352.

10 Hendrikse J, Klijn CJ, van Huffelen AC, Kappelle LJ, van der Grond J: Diagnosing cerebral collateral flow patterns: accuracy of non-invasive testing. Cerebrovasc Dis 2008; 25:430-437.

11 Chimowitz MI, Lynn MJ, Howlett-Smith H, Stern BJ, Hertzberg VS, Frankel MR, Levine SR, Chaturvedi S, Kasner SE, Benesch CG, et al: Comparison of warfarin and aspirin for symptomatic intracranial arterial stenosis. N Engl J Med 2005;352:1305-1316. 
12 Yu SC, Leung TW, Lee KT, Hui JW, Wong LK: Angioplasty and stenting of atherosclerotic middle cerebral arteries with Wingspan: evaluation of clinical outcome, restenosis, and procedure outcome. AJNR Am J Neuroradiol 2011;32:753-758.

-13 Adams HP Jr, del Zoppo G, Alberts MJ, Bhatt DL, Brass L, Furlan A, Grubb RL, Higashida RT, Jauch EC, Kidwell C, et al: Guidelines for the early management of adults with ischemic stroke: a guideline from the American Heart Association/American Stroke Association Stroke Council, Clinical Cardiology Council, Cardiovascular Radiology and Intervention Council, and the Atherosclerotic Peripheral Vascular Disease and Quality of Care Outcomes in Research Interdisciplinary Working Groups: the American Academy of Neurology affirms the value of this guideline as an educational tool for neurologists. Stroke 2007;38:1655-1711.

14 Guidelines for management of ischaemic stroke and transient ischaemic attack 2008. Cerebrovasc Dis 2008;25:457-507.

15 Higashida RT, Furlan AJ, Roberts H, Tomsick T, Connors B, Barr J, Dillon W, Warach S, Broderick J, Tilley B, et al: Trial design and reporting standards for intra-arterial cerebral thrombolysis for acute ischemic stroke. Stroke 2003;34:e109-e137.

16 Liebeskind DS, Cotsonis GA, Saver JL, Lynn MJ, Cloft HJ, Chimowitz MI: Collateral circulation in symptomatic intracranial atherosclerosis. J Cereb Blood Flow Metab 2010; 31:1293-1301.
17 Brunser AM, Lavados PM, Carcamo DA, Hoppe A, Olavarria V, Diaz V, Rivas R: Additional information given to a multimodal imaging stroke protocol by transcranial Doppler ultrasound in the emergency room: a prospective observational study. Cerebrovasc Dis 2010;30:260-266.

18 Kim JJ, Fischbein NJ, Lu Y, Pham D, Dillon WP: Regional angiographic grading system for collateral flow: correlation with cerebral infarction in patients with middle cerebral artery occlusion. Stroke 2004;35:13401344.

19 Kucinski T, Koch C, Eckert B, Becker V, Kromer H, Heesen C, Grzyska U, Freitag HJ, Rother J, Zeumer H: Collateral circulation is an independent radiological predictor of outcome after thrombolysis in acute ischaemic stroke. Neuroradiology 2003;45: 11-18.

20 Christoforidis GA, Mohammad Y, Kehagias D, Avutu B, Slivka AP: Angiographic assessment of pial collaterals as a prognostic indicator following intra-arterial thrombolysis for acute ischemic stroke. AJNR Am J Neuroradiol 2005;26:1789-1797.

21 Kim JT, Park MS, Choi KH, Nam TS, Choi SM, Cho KH: Clinical implications of collateral middle cerebral artery flow in acute ischaemic stroke with internal carotid artery occlusion. Eur J Neurol 2011;18:1384-1390.
2 Henderson RD, Eliasziw M, Fox AJ, Rothwell PM, Barnett HJ: Angiographically defined collateral circulation and risk of stroke in patients with severe carotid artery stenosis. North American Symptomatic Carotid Endarterectomy Trial (NASCET) Group. Stroke 2000;31:128-132.

23 Rossini PM, Calautti C, Pauri F, Baron JC: Post-stroke plastic reorganisation in the adult brain. Lancet Neurol 2003;2:493-502.

24 Wei L, Erinjeri JP, Rovainen CM, Woolsey TA: Collateral growth and angiogenesis around cortical stroke. Stroke 2001;32:21792184.

25 Choi JW, Kim JK, Choi BS, Lim HK, Kim SJ, Kim JS, Suh DC: Angiographic pattern of symptomatic severe M1 stenosis: comparison with presenting symptoms, infarct patterns, perfusion status, and outcome after recanalization. Cerebrovasc Dis 2010;29: 297-303.

26 Kim SJ, Ryoo S, Kim GM, Chung CS, Lee $\mathrm{KH}$, Bang OY: Clinical and radiological outcomes after intracranial atherosclerotic stroke: a comprehensive approach comparing stroke subtypes. Cerebrovasc Dis 2011; 31:427-434.

27 Chimowitz MI, Lynn MJ, Derdeyn CP, Turan TN, Fiorella D, Lane BF, Janis LS, Lutsep HL, Barnwell SL, Waters MF, et al: Stenting versus aggressive medical therapy for intracranial arterial stenosis. N Engl J Med 2011;365: 993-1003. 